\title{
How to Reverse the Italian Brain Drain: A master class from Australia
}

\begin{abstract}
This article discusses the limits of Italian immigration policies and their effects on the Italian market of highly skilled individuals. Highly skilled individuals are normally perceived as valuable resources that a country should foster and even, if possible, attract from other states (Meyer and Brown, 1999). Unfortunately, Italian statutory provisions aimed at regulating immigration focus on limiting immigration without a reasoned distinction between skilled and unskilled immigrants.

The paper reflects on the reasons for the parochial structure of the Italian white-collar market which is mainly cultural - and its effects. In the past decades, Italy's private and public sectors have suffered the effects of a "brain drain" of a wide range of highly skilled professionals (Becker, Ichino and Peri, 2003). A series of reasons, such as the fact that Italy is - and has been for some time - one of the world's most sluggish, heavily industrialised economies (Hornby, Mackenzie, 2011), might explain the departure of skilled individuals from the Italian job market. Italy's lack of economic growth in the private sector (and the related high unemployment rate) "pushes" away highly skilled individuals from areas of oversupply (e.g. Italy) to strong economies (e.g. Australia) where particular abilities are in demand.

The paper would like to address the issue by suggesting the introduction of a medium/long-term visa for highly skilled individuals (Ottonelli and Torresi, 2010), and by promoting the establishment of private multinational universities modelled on the European Institute in Florence. These new institutions would open the academic job market to overseas researchers and at the same time provide a more solid base for the retrieval of Italian academics working abroad. The paper is divided in two sections which are preceded by an introduction. The first section deals with the Italian immigration statutory provisions. The second explains the policies that might increase the efficiency of the Italian market for elite employees.
\end{abstract}




\section{INTRODUCTION}

The present economic crisis is endangering the future prosperity of the Italian economy. A decade of slow growth followed by a deep economic financial crisis has had a negative impact on the Italian private sector. In comparison with the private sector, the Italian public sector has suffered indirectly from the country's lack of economic performance. High levels of tax evasion and two decades of slow economic development have yielded one of the largest sovereign debts in Europe. During the nineties, in an attempt to "balance the books" and to comply with the Treaty of Maastricht, the Italian government reduced employment in the public sector to a trickle and at the same time curtailed investments in research (De Vivo, Trigila, Panza, and Peccerillo, 2006). The reduction of job opportunities is, in part, exacerbated by an unofficial public sector employment praxis called "clientelism", which favours the recruitment of a small pool of individuals (e.g. family, business friends) that prioritise loyalty above meritocracy (Caciagli, 2006; 158). Caciagli's analysis suggests, for instance, that two decades of weak public sector demands have strengthened the incidence of clientelism. It is therefore not surprising that Italian researchers moved to countries with strong economic perspectives, such as Australia.

It is also not unreasonable to speculate about the effects of a lack of "know-how" in areas such as policy making. The lack of understanding is particularly evident in new policy areas such as immigration and naturalisation. In the past 20 years, Italy has become a destination for mass lowskilled immigration, yet Italian statutory provisions, such as the Testo Unico sull' Immigrazione (1998), have tried to reduce immigration by targeting specific crimes (e.g. the ones violent by nature) and by restricting naturalisation procedures (Aliziano, 2010, Breda and Calvanese, 1998; Calvanese 2011). However, the same procedures that target low-level skilled immigrants also affect highly qualified individuals, limiting the Italian opportunities for overseas highly skilled individuals (e.g. researchers and business managers). ${ }^{1}$ The restriction in the job market, in turn, contributes to the lack of competiveness in public sector jobs (already affected by the combined effects of the economic downturn and clientelism) and reduces the country's ability to advise and design policies that grapple with present problems. In short, two decades of Italy's economic underperformance stimulates a vicious circle in which the brain drain progressively depletes the country's ability to retain highly qualified individuals who logically ought to be the prime actors in a future recovery.

It is not all "doom and gloom". Italian researchers who emigrated to strong economies such as Australia might eventually return to their homeland and bring back additional skills. Statistical studies suggest that developing countries might retrieve highly skilled individuals who matured 
their abilities abroad (Meyer and Brown, 1999). Italy is not, by any means, an emerging economy, but some of Meyer's and Brown's assessments might help retrieving highly skilled Italians working abroad.

However, I would argue that the retrieval of the Italian lost brains has to be part of a reform of the Italian white-collar job market that guarantees openness and meritocracy. Specifically, this paper discusses the potential benefits of adopting short and medium-term visa schemes for highly skilled individuals. The policy would combine: an assessment of immigrant skills (perhaps similar to the evaluation chosen by the Australian Skilled Independent Visa) with Torresi' and Ottonelli's idea of temporary work projects (2010). The temporary work projects are visa schemes designed around the needs (e.g. equality of work conditions and financial support in case the project fails) of a provisional worker.

I would also argues that an increase in the quality and quantity of skilled individuals in the market might not dislodge the practice of clientelism in Italian research institutions. It is also improbable that a policy that seeks to squarely reform such a practice might have the effect of diminishing its pervasiveness. Studies of these types of networks of relations indicate that any reform might be ineffective (Caciagli 2006) or produce the opposite of the desired expectation (Bauman 2001). Italian clientelism creates a stable system of relationships that react against any pressure to reform (Caciagli 2006).

However, the low performance of the Italian academia compared to other first-world countries might produce a strong narrative for the development of a policy of multinational private institutions. For instance, according to the World Ranking of World Universities (2011), Italy is one of the few industrialised nations without a top 100 research institution. The multinational universities based on the model adopted by the European Institute in Florence would have the task to cover such a gap in research outputs, and they would also be the ideal receptacles for : highly-skilled immigrants and for Italian researchers working overseas.

Before turning to the substantiation of my claims, a series of qualifications has to be inserted as a preliminary discussion. I will use the term clientelism as defined in Caciagli as "an informal network of power relations between individuals" (2006; 158). The practice of clientelism, which originated in rural societies, included an informal vertical power relation between the power holder (e.g. the patron/landowner) and a number of inferiors (e.g. seasonal workers). However, the new Italian clientelism is horizontal and might include a nationwide network of individuals that exchange tangible favours (e.g. jobs, public contracts, political votes) at national level (2006; 
159). The problem of clientelism is sometimes associated with nepotism in terms of which members of a family receive undue benefits. Whilst there is strong evidence that the distribution of Italian academic positions is affected by nepotism (Allesina, 2011), the unfair allocation of vacancies to members of a family is only one of the aspects of clientelism. In Caciagli's analysis, for instance, the possibility of exchanging tangible undue benefits includes a very large community (2006). It includes, for instance, individuals that are promoted in the ranking of the network for their political associations but who have no family ties with an academic patron.

Furthermore, there are distinctive limitations in the Italian job market to highly skilled individuals, such as the requirement of fluency in Italian as a spoken language. My argument here is not that a knowledge of Italian is relevant to an immigrant's decision before emigrating but highly skilled activities (e.g. finance, engineering, and medical studies) might not require fluency. English has become the new elite's lingua franca.

The essay is divided into two sections. The first section discusses the immigration policy in Italy. It will argue that a combination of historical and sociological factors makes Italy uncompetitive in the global market of highly skilled individuals. The second part of the essay discusses the advantages of two short-medium term policies: first, a visa scheme based on Ottonelli's and Torresi's idea of temporary work projects (2010) and second the establishment of multinational institutions.

\section{A CHOKING TIE FOR WHITE-COLLAR ASPIRATIONS IN ITALY}

Italian statutory provisions on immigration, residency, and citizenship are inadequate to develop a competitive internal job market that might attract Italian and foreign-skilled professionals working overseas (Di Bari, Zordella, 2008,). For instance, visa schemes adopted in other countries such as the Australia General Skilled Migration Program streamline applications and facilitate the process of obtaining permanent and/or temporary residency.

There are distinctive historical reasons for the relative closure of the Italian immigration policy. Immigration is a relatively new phenomenon in Italy. It was only after the 1980s that Italy became a destination of mass immigration - mainly from North Africa and the former communist countries (Breda, and Calvanese, 1998). The regulatory framework that hosted the first waves of immigrants was set in articles $142-149$ of the 1931 Testo Unico delle Leggi di Pubblica Sicurezza (hereafter TULPS). The articles were designed during the Fascist regime and set a series of strict limitations on travel, dwellings, and the employment of foreigners (Calvanese, 2011; 47). 
Even a cursory reading of TULPS reveals the signs of the police regime that gave birth to it (Regio Decreto n.773, 1931). For instance, foreigners who already had a visa had three days from the moment of entering the country to request a local 'resident permit' from the police constabulary (Regio Decreto n.773, 1931; 142). Landlords (or lease holders who might be relatives) hosting foreigners had only 48 hours to notify the local constabulary (Regio Decreto n.773, 1931; 147). Employers were also affected by the regulation. They were obliged to inform the police of the nationality of their workforce, and in case of dismissal, to inform the same constabulary of the "probable destination" of the non-Italian citizen (Regio Decreto n.773, 1931; 146). Revoking the resident permit was the most common sanction for the violation of any of the above statutory dispositions (Regio Decreto n.773, 1931; 148). In brief, foreigners were "heavily monitored administrative licence holders" rather than rights bearers.

Long before the 1990s reforms, the statutory provisions (and their sanctions) might have given rise to a question of constitutional compatibility. Yet, in practice, the norms regarding foreigners were widely ignored by all concerned. Administrative inefficiency played a part in making TULPS ineffective. The administrative unit within the police constabulary charged with the task of authorising foreign residency, called Ufficio Stranieri, has similar functions as the Australian Borders Patrol but is often understaffed. It was common for foreigners to wait for months for resident permits, forcing them into areas of illegal residency and then illegal work.

At pragmatic level admistrative inefficiency mediated a draconian regulatory system (Calvanese 2011). During the 1990s, a series of reforms intended to change the plight of the foreigners in Italy from precarious administrative licence holders to "rights bearers" (Legge. 28, 1990, Legge n.286, 1998). In particular, the Legge n.286 "bundled" all the new statutory measures together in a codification called: Testo Unico delle Disposizioni Concernenti la Disciplina dell'immigrazione e Norme sulla Condizione dello Straniero (hereafter TU). First, the TU introduced a rationalisation of the work visas. Second, it established an electronic database of all foreigners that explicitly asked to work in Italy. Third, it streamlined the immigration procedures and integration (Legge n.286, 1998: 21-22). Fourth, the TU set out a specific category of highly skilled immigrants who were not affected by immigration quotas. Other categories not limited by the T.U. immigration quota were professional athletes, nurses, and journalists.

However, in the decade that followed the approval of the TU, there were few signs that Italy attracted more highly skilled professionals than the decade before (Fullin and Reyneri, 2010). As in other sociological tendencies, there are a series of reasons that might explain Italy's lack of appeal as a destination for immigrants. Again the Italian economy was not growing as fast of 
other industrialised economies (Hornby, Mackenzie, 2011). But it is also plausible to argue that TU regulations might have dampened the enthusiasm of those highly skilled immigrants who considered Italy a potential destination for relocation.

First, some of the negative aspects of TULPS outlived the reforms. For instance, the TU maintained many of the restrictions of the resident permit system designed for all immigrants (Legge n.286, 1998: 5) and the measures that were aimed at creating a more appealing environment for immigrants by fostering integration and intercultural exchange remained unapplied (Legge n.40, 1998; 36).

Second, in the public sector, senior research positions the TU opened to overseas applicants remain limited by official (e.g. a ministerial authorisation for chairs) and unofficial practices (e.g. clientelism) that tend to advantage internal candidates with a powerful patron within clientelism network. Even junior positions that can be acceded via a national competition require "trip to Italy" (probably with a tourist visa), sitting an exams, and in case of success, the winning candidate must return to the country of origin and request a work visa. As is the case with senior positions but to a lesser degree, the junior research vacancies are likely to be affected by the praxis of clientelism.

Third, the TU provides a strict regulatory designation of who are highly skilled professionals. The definition includes only an elite group of individuals who work for a multinational company with a branch in Italy and have a role within the same company as a company director. The rationale appears to be directed at facilitating the internal movement between multinational companies rather than an attempt to open the market of white-collar jobs.

To illustrate the impact of such restriction, let me show the process of a highly qualified professional, let us call her Amy Cameron, would have to go through if she intended to relocate to Italy. Amy holds a degree in marine biology from Australian National University, a master's degree from Amsterdam University, and a Ph.D. in Environmental Studies from Cardiff University. She is also a senior manager at Environmental Impact Limited based in Cairns. She were looking for a position in either the private or public sectors. Unfortunately, Environmental Impact is not a company that has a branch in Italy nor does Ami have a director's role in the company. The first task for Amy is to add her name (by post) to a database of overseas jobseekers accessible to Italian employers (Legge n.286, 1998: 32). Whilst the list is not ranked by the level of qualifications (it is based on the date of application), it might give skilled individuals the opportunity to be selected by an Italian firm. However, Caciagli's analysis of the impact of 
clientelism suggests thatprivate employers might prefer to seek among friends, families, and the network of individuals that are part of their clientelism network before actively searching the list of overseas jobseekers (2006). This analysis is confirmed by the statistical research of (Fullin and Rayneri, 2010). In nutshell, Amy's chances to have her name cherry-picked from the list of overseas job seekers are very slim.

Before 2011, an additional path to entry into the Italian job market for highly skilled immigrants was via an immigration quota (decided annually in collaboration with central and regional institutions). The immigration quota relied on a list of allocations divided by country of origin and employment sectors. It was not designed to attract qualified individuals. Both the countries selected for a specific quota (mainly third and second-world countries) and the sectors (e.g. agriculture and building) are traditional reservoirs of low-skilled temporary workers. At any rate, following the latest Italian financial crisis, the immigration provided by the quota has been suspended.

"Bad timing", Amy might think, but a casual stroll in front of Cairns City Hall gives her a new idea. Walking past the gate, she notices that Cairns City Council posted a local list of needed skilled professionals and tradespersons as part of the Australia Skilled Regional Sponsored Visa. Given the variegation of economic development in Italy, she thinks, similar initiatives might be carried out in different parts of Italy that are in need of specific skills and are less affected by the economic downturn. Amy is indeed right.

In theory, she could browse the regional lists of required overseas employees (Legge n.286, 1998, 21) in northern regions of Italy that have specific demands for marine biologists (e.g. Venice) and environmental impact, such as the Alpine regions. Unfortunately, the lists of required job vacancies (that were not filled by Italian or EU citizens) have never been drawn up, and even if they have been, she most probably would have had to ask to have them posted to her address in Australia since the TU regulation does not include a requirement of publicity. The failed compliance is particularly unsettling in the rich and heavily industrialised North. For instance, the region around Venice has experienced two decades of substantial economic growth, but at the same time has, by way of comparison to other EU economies, supplied a low level of graduate workers (Direzione Sistema Statistico Regionale, 2010). It is again a matter of speculation, yet statistical analyses suggest that in Italy, a high level of education of overseas workers is not rewarded by a correspondent job allocation (Fullin and Reyneri, 2010). Specifically, Fullin and Reyneri argue that non-European citizens who might not be discriminated against in low skilled jobs are disproportionally unrepresented in managerial positions (2010). 
As mentioned earlier, there is a plurality of factors that make highly skilled individuals particularly uninterested in the Italian job market. Chief among them is the fact that the country experienced ten years of slow economic performance, but even in local areas of robust economic growth, discriminatory practices and combined idiosyncrasies of official immigration policies put the Italian economy at a disadvantage. In particular, statutory policies that regulate immigration in Italy appear to hinder the development of an open market for highly skilled individuals. The argument here is not that the market for qualified individuals is not competitive. Rather than by putting highly qualified individuals such as our Amy through a series of administrative tasks, some of which are a dead end (e.g. the insertion on the list of overseas employees), the regulatory system discourages the immigration of talented individuals and all the human capital attached to it

\section{TEMPORARY WORK PROJECTS AND MULTINATIONAL UNIVERSITIES}

In this section I would like to suggest two immigration policies that might improve the competiveness of the Italian highly skilled job market. The first suggestion is to establish a new category of temporary work visas for white-collar overseas workers based on their specific needs. The new policy is drawn from Torresi's and Ottonelli's idea of temporary work projects (2010). Second, to reduce the effect of clientelism, I would suggest there might be the need to establish a series of private research institutions, perhaps modelled on the European Institute in Florence, in which the assessment of academic performance is done by multinational referees.

The space of the paper limits the amount of details that supports either proposals, yet the aim is to show the possibility, in theory and practice, of increasing the attractiveness, the so-called "pull factor", of the Italian job market for highly skilled professionals. The two proposed policies are short and medium-term suggestions aimed at adjusting the unbalanced situation and, finally, at helping to re-start the country economy.

\section{a) The temporary work project visa for highly skilled professionals: a master class from Down Under}

Italian immigration policies, derived from an unfortunate past, and the TU might have allowed some of the aspects of the previous regime to outlive the 1990s reforms. In the regulation of immigration of highly skilled immigrants, for instance, there are strong indications that the TU aims at controlling the entry of skilled individuals rather than gathering an essential economic resource. However, I would like to suggest that a relatively small adjustment to the TU might 
help talented individuals who work overseas. For instance, the introduction of temporary work projects to allow skilled individuals, like Amy, to work in Italy for a medium/long period of time.

The idea of temporary work projects was recently suggested by Valeria Ottonelli and Tiziana Torresi. Ottonelli is based at Genoa University and Torresi at Adelaide University, but both researchers moved backwards and forwards between Europe, America, and Australia. They noted that a large group of immigrants decide to migrate on the basis of a life plan (2010). The life plan might include a destination, a type of job, a level of aspired integration, and a time to return to the country of origin. However, the state policies that seek to regulate those choices tend to mediate between ideological stances. On the one hand immigration policies defend liberal aspirations of market efficiency and, on the other hand, they manifest a concern about the perceived invasion of low-skilled immigrants. The tension between the two stances cannot be accommodated at a normative level (at their core the ideas of strictly ethnic nation-state and cosmopolitan open liberalism are antithetical), yet most countries have a tendency to set policies that, depending on the particular socio-economic circumstances, are on a point of the spectrum between the defence of the ethnic state and open borders. The TU favours an ethic centred policy (Aliano, 2010).

The Italian immigration policy finds a normative justification in what Ottonelli and Torresi call the liberal inclusionist model. In the liberal inclusionist model aliens are allowed in a country with limited legal rights (to satisfy the concern of those who believe that a state should have a permanent national community), but immigrants undergo a process of integration that will quickly grant them the status of citizens. "Liberal inclusivists [...] by coming fully to terms with the cosmopolitan spirit of egalitarian liberalism, accept its normative implications for the issue of membership. Their position consists of two arguments. First, the acceptance that the separation between states and the existence of citizenship rights are tied to a specific political community [...] However, and second, liberal democracies should be loyal to their cosmopolitan values and apply a liberal and inclusive policy to those who wish to move to their territory." (Ottonelli and Torresi, 2010, 4).

The liberal inclusionist is, to put it simply, a pragmatic response to what is perceived as a temporary situation. In an ideal - liberal - world, where democracy has spread in all countries and the free market has fostered a worldwide level of economic prosperity, there are fewer compelling reasons for immigrating and the reduction in the number of relocating individuals will proportionally reduce the concerns of nationalists (for an analysis of the legal implications of 
an ideal cosmopolitan society, see, for instance: Held, 1995). But Ottonelli and Torresi are unconvinced by the liberal inclusionist model.

Individuals might continue, they argue, to migrate, even if those ideal conditions envisaged by liberal inclusionists were realised, because individuals often want to experience life in a different setting. The argument developed by Ottonelli and Torresi is not that immigration might not be reduced by the spread of democracy and economic prosperity. Rather they suggest that the liberal inclusionist model does not consider the full implications of the freedom to pursue individual aspirations (e.g. happiness, a good life, etc.) that are pivotal factors of individual decisions $(2010 ; 5)$.

The policy, proposed by Ottonelli and Torresi, to cater for these life choices is, I think, enlightening and it might be appealing for a new Italian immigration regulation. Ottonelli and Torresi suggest that the state should devise a policy that caters specifically for those individuals who perceive immigration as a matter of choice. The choice to emigrate is, for these individuals, a temporary step that might enhance their CV, economic wealth, as well as cultural enrichment. However, most of these individuals will return to their homeland (Ottonelli and Torresi, 2010). Once in their homeland, temporary immigrants might contribute to their personal careers and the development of their own national economy (Meyer and Brown, 1999).

The return home is the distinctive aspect of temporary immigration. From a series of quantitative and qualitative analyses, Ottonelli and Torresi show that temporary immigrants have a tendency to work more hours than citizens (or permanent immigrants), postpone the disposal of earnings (sometimes for the development of a different life project), and normally do not engage in political activity that is perceived as threatening to the stability of a national community $(2010,9)$. Whist these factors should make the establishment of temporary working visa for highly qualified individuals very appealing to all industrialised countries, they should be particularly appealing to economies like the Italian that might need a short time burst of resources to overcome the worst aspect of the present economic crisis.

It should be noted that the idea of temporary work visas might stimulate a series of objections. For instance employers might exploit the status of temporary immigrants. In the case of highly qualified individuals, I would argue that the concern is more theoretical than practical. In Italy, immigrant workers have the same level of safeguard as citizens. It is also reasonable to expect that highly skilled individual, by a way of comparison with low skilled workers who might have problem with language and might be intimidate by an alien administration should have the 
ability to retrieve information and demand the protection of their working rights. For instance, a highly qualified individual such as Amy might not be concerned about the temporary nature of her status if she knows that her general work conditions would be as protected as those of any other Italian employee.

Let me recall that, an immigration policy cannot be designed to create substantial equality. For instance, a company might not pay Amy the same wage as a temporary visa holder since s/he might not produce the same long-term rewards to the company as an Italian citizen. However, the argument works only to a degree. The acceptance of the less favourable condition is, for instance, Amy's personal life choice which is counterbalanced by the experience she is gaining by working abroad.

A series of safeguards might also mitigate the potential side effects of temporary work project visas. For instance, the temporary visa might not be linked to working for the entire period of residency and might include financial insurance that deals with the cost of repatriation. The financial guarantee to return home was suggested by Ottonelli's and Torresi's articles to protect low-skilled workers $(2010,19)$. We know that low-skilled workers might find themselves pushed into 'illegal inhumane work conditions' (Calvanese, 2011). Nevertheless I would argue that a financial safeguard for the cost of repatriation might also make a policy aimed at attracting temporary highly-skilled workers distinctively more appealing. It might, for instance, add considerable interest to a scheme for young professionals who might be highly qualified but have not got large savings.

Some of the minute aspects of Ottonelli's and Torresi's proposal are discussed at length in their article and could not all be reproduced here. However, some pragmatic points are worth noting. For instance, the temporary immigration projects policy will require a system that evaluates qualifications, job experience, and age. The institutional problems of the Ufficio Stranieri (e.g. a culture of administrative control) might be mitigated by the allocation of clerical work to private firms. The system is used already by emerging economies that seek to attract highly skilled individuals and want to facilitate the visa procedures but do not have the administrative capacity for delivering an expedite service .

\section{b) New Multinational Universities}

The second policy I would like to suggest aims at promoting the establishment of new private multinational universities modelled on the European Institute in Florence. The policy of favouring the formation of new multinational universities has a twofold objective. On the one 
hand, it aims at retrieving researchers working overseas (e.g. Australia and the US) by enlarging the receptive capacity of Italian universities without impinging on precarious public finances. On the other hand, it aspires to evade the effect of clientelism. Multinational University should attract highly skilled individuals working abroad on merit that is potential benefits they might bring to the research institution (rather than a patron). In addition it is also reasonable to speculate that enlarging capacity of Italian Academia might attract Italians currently working abroad who normally work in a multinational environment.

Italian public universities are particularly affected by depleted economic resources, the lack of a culture of meritocracy and the problem of clientelism. All three of these problems might require a long-term solution but a distinction might be drawn between stricto senso economic problems and those that are cultural. Even before the economic downturn, Italian academia had to manage a challenging financial situation (De Vivo, Trigila, Panza, and Peccerillo, 2006; Ruggio, 2008; 13 Rossi, 2008, 29) that will not be discussed in this paper. I would like to reflect instead on the feasibility of "low cost" (for Italian public finances) immigration policies that might help reducing the pragmatic effect of clientelism.

Caciagli argues that modern Italian clientelism is formed by a network of individuals with an internal political affiliation, rites, values, and symbols, who exchange tangible benefits (e.g. jobs, research funds). Whilst it originated in an agricultural society, clientelism has a distinctive appeal in a globalised society (2006). For instance, the network of clienteles provides security - by informally bypassing strict meritocratic tests - and economic benefits by unfairly allocating resources to its members (2006). This is not a distinctive Italian problem. Bauman, for instance, referred to the metaphor of the "fortress under siege" to describe a cultural community he perceived as a side product of globalisation. " 'Culture' [for the members of a clientelism network] is synonymous with a besieged fortress, and in a fortress under siege, the inhabitants are required to manifest unswerving loyalty daily and to abstain from any hobnobbing with outsiders" (Bauman, 2001; 101). Bauman's description of a culture of informal partnerships is very general sociological deduction, but The important point I would like to drwo here form both Caciagli and Bauman is that Italian clientelism (with its deeply embedded relations with political sphere) is unlikely to be altered in an economic crisis exactly because it is providing security to those who are part of the network designed to resist social and economic uncertainty.

So, the resilience of clientelism might justify a solution that does not directly change the stability of the Italian academia. Developing this point, I would like to argue that by favouring the creation of new multinational universities, it might be possible to enlarge the academic job 
market, and in turn, increase Italy's appeal as a destination for overseas researchers. To start with, in Italy there already is a well-established multinational university - the European Institute in Florence. There are also several foreign university branches that might not be subject to the effects of Italian clientelism. For instance, Monash University has a branch in Tuscany, and New York University has a branch in Rome. These institutions might provide the springboard for a more general policy. In particular I would suggest that by increasing the financial benefits (by reducing tax and providing long-term free leases to land and building used by these institutions) Italy will attract more elite academics (at any stage of their career) to Italy.

The most obvious evidence of the potential benefits of the proposed policy is drawn from the successful history of the European Institute in Florence. The European Institute started operating in 1976 and was the result of an inter-governmental agreement between, at the time, European Community Member States. Its aim was to promote studies that might help European integration but European Institute research portfolio went beyond the original mandate (Convention setting up a European University Institute, 1972, Art 2), transforming it into a formidable research institution in areas such as social, legal and economic studies.

In contrast to Italian institutions, the European Institute favours multi-nationalism. It was indeed one of the key criteria that allowed the 1970s' Europe Community Members to agree on its creation. For instance, the 1976 convention guaranteed the multinational management structure of the Institute by imposing a national quota of its directors and, at the same time, the rigour of its financial administration. For instance, the finances of the European Institute are verified by an external team of multinational auditors. Finally, the Italian Republic committed itself to providing for the cost of the infrastructure (mainly buildings and land).

I would like to argue that the imposition of multinational management, an external multinational audit, and the long-term free leases of the facilities should become part of a general policy aimed at improving the competiveness of Italian-based private universities. These new institutions, it is reasonable to argue, will be, by design, attractive to highly skilled individuals who are seeking job opportunities in Italy. Furthermore, multinational institutions will also attract lost brains. That are talented Italians working in overseas institutions by giving them the possibility of long-term career opportunities.

For several years, the Minister of Education tried a policy aimed at recovering lost brains. They were for the great majority individuals, at the medium stages of their careers, who might have been penalised by not having a powerful enough "patron" within the clientelism network. The 
scheme had limited success (Rientro dei Cervelli, 2008). After five years, only a small number (in 2008, 40 of the 500 Italian researchers that had relocated to an Italian institution) were offered a permanent position. The very low retention rate (and waste of resources attached to it) appears to be related to difficulties with the management of human resources and financial restrictions (Rossi, 2008), but there is also a strong indication that the low retention rate might have to do with clientelism. That is, Italian researchers with different degree of overseas experience, find themselves competing for a limited number of senior positions against individual who have over the years in Italy matured a series of strong connections within the network.

Is it a rather unnecessary fuss? The idea of setting a policy of private multinational universities to reduce the impact of clientelism might appear excessive. Exceptionally gifted individuals might be helped, not hindered, by the informality of the clientelism network. For instance, patrons might actively look for highly skilled individuals (Italian or foreigners) to attract economic projects from overseas (e.g. the EU). The informal flexibility of clientalism might, for instance, actively scout for Italian researchers with a track record of sourcing revenues. My concern is that the positive aspects of clientelism cannot be left to the "goodwill" of a group of patrons who might little interest on developing an Italian world class research. Rather, a systemic rebalance of the academic market (that fosters openness, efficiency and meritocracy) is, I would argue, a necessary step in improving the country's ability to retrieve Italian talents and, in turn, helping its present economic down-spiral.

\section{CONCLUSION}

Creating the institutional conditions for attracting the expertise of highly skilled individuals from places like Australia might, among other factors, help Italy recover from the present crisis and develop a condition of economic flourishing. In the first section of this paper I discussed Italian immigration policies. I argued that they might have derived from an unfortunate past (a 1930 police regime) and the 1990 reforms might have inherited an "institutional culture" of administrative control. There are also strong indications that public sector deficiencies combined with private dysfunctional recruitment procedures (e.g. clientelism in Caciagli and discrimination in Fullin Rayneri) might be to blame for a series of unjustifiable bottle necks in the job market of highly skilled professionals.

However, independently from the possible reasons for the present situation, a series of small policy changes with relatively little cost for public finance might increase Italy's appeal as a destination for highly qualified individuals. In the second section of the paper, I argued, for 
instance, that a policy drawn from Torresi's and Ottonelli's ideas of temporary work project visas might increase Italy's appeal in the market of highly qualified individuals. Ottonelli and Torresi are senior researchers who have worked both in Italy and abroad. Their proposal shows an in-depth personal understanding of the special requirements of relocating white-collar workers and an awareness of the policies adopted in Australia (e.g. the Australian Skilled Independent Visa) to streamline relocation procedures. In contrast, for instance, to the Italian present regulation, the temporary work projects for the highly skilled promote rights (e.g. equality in work conditions and career progression for aliens) and services (e.g. a financial safety net in case the migration project fails) for overseas white-collar immigrants.

The temporary work project visas might also help reduce the endemic problems of the Italian academia. In particular the area of academic research (which is mostly publicly founded) is, and has been for a long time, one elective area of clientelism. Italian clientelism tends to create a network of individuals in which patrons exchange tangible favours and develop a culture based on loyalty above meritocracy. Clientelism, as a reaction to limited resources, cannot be exclusively cured by an officially open market (brought by temporary work projects) since clientelism relies on the informal exclusion of outsiders.

So to grapple with clientalism, I suggested a policy that should help setting new private universities and expanding the branches of those already in Italy. The suggestion is based on the success story of the Europe Institute in Florence. The institute, for over three decades, has functioned as multinational administrated high education establishment that seeks to attract qualified individuals and promote world-class research. The guarantee of multi-nationality of its administration (both in managerial and financial terms) allowed the institution to prosper in a way that might be replicated in new private institutions. The new multinational universities would expand the capacity of the Italian higher education sector market for highly qualified individuals and should, also, stimulate the return ofthe lost brains who, at present, are working in overseas institutions, by proving to provide long-term career opportunities not offered by the public sector.

\section{NOTE}

1. The explanation for the present Italian legal response to a global phenomenon is indeed multifaceted. For instance, in the past two decades, Italy was governed by a coalition that included nationalist and regionalist political parties with open xenophobic agendas, yet there are strong indications that there is more than simple irrational parochialism in the Italian development of immigration policies. 


\section{BIBLIOGRAPHY}

Aliano, D.,

2010 "Citizenship and Belonging: The Case of the Italian Vote Abroad", Ethnic Studies Review, n. 33/1, 36-60.

Allesina, S.,

2011 "Measuring Nepotism through Shared Last Names: The Case of Italian Academia", PLOS ONE, n. 6/8,

Bauman, Z.,

2001 Community : Seeking Safety in an Insecure World, Themes for the 21st Century, Polity Press, Oxford.

Becker, O., Ichino A., and Peri, G.,

2004 "How Large is the "Brain Drain" from Italy?", Giornale degli Economisti e Annali di Economia, n. $63 / 1,1-32$

Breda, V, and Calvanese, E.,

1998 "La delittuosità degli immigrati nel Comune di Milano (1991-1996): è vero aumento?", Rivista Italiana di Criminologia, n. 3, 32-42.

Caciagli, M.,

2006 "The Long Life of Clientelism in Southern Italy", in Kawata , J (Eds) Comparing Political corruption and clientelism, Ashgate, Oxofrd: $158-169$.

Calvanese, E.,

2011 Media e Immigrazione Tra Stereotipi e Pregindiæi, Franco Angeli, Rome.

De Vivo, B., Trigila, R., Panza, G., and Peccerillo A.,

2006 "Italy's investment in research", Eos Transaction, n. 26/87, 258-271,

Di Bari, P., and Zordella N.,

2008 "Presentazione" Diritto, Immigrazione e Cittadinanza, 3/4, v-vi.

Direzione Sistema Statistico Regionale,

2010 The Region Veneto in Figures, Venice,

Fullin G., and Reyneri, E.,

2011 "Low Unemployment and Bad Jobs for New Immigrants in Italy", International Migration, $1 / 49,118-147$ 
Held, D.,

1995 Democracy and the Global Order : From the Modern State to Cosmopolitan Governance. Polity, Cambridge.

Hornby, C. and Mackenzie, J.,

2011 'Bank of Italy warns weak growth could bit debt plan' Reuters,

Available at: bttp:// wmw.reuters.com/article/2011/08/30/italy-austerity-

idUSLDE77T08J20110830> [Accessed on the 30th of September 2011]

Member States of the European Community

1972 Convention setting up a European University Institute,

Available at: http://www.eui.eu/Documents/AboutEUI/Convention/English.pdf

Accessed: 10/01/2012

Member States of the European Union

1992 Convention revising the convention setting up a European University Institute, Available at:

http://www.eui.eu/Documents/AboutEUI/Convention/ConventionRevising.pdf Accessed:10/01/2012

Meyer, J, and Brown, M.,

1999 "Scientific Diasporas: A New Approach to the Brain Drain". Sociology Paper, UNESCOICSU, N.41, 1-21.

Ministro dell' Interno (Mussolini, B.,)

1931 Testo Unico delle Leggi di Publica Sicurezza, Regio Decreto n.773, Rome.

Ottonelli, V. and Torresi, T.

2010 "Inclusivist Egalitarian Liberalism and Temporary Migration: A Dilemma." Journal of Political Philosophy, Forthcoming, Available at:

http://onlinelibrary.wiley.com/doi/10.1111/j.1467-9760.2010.00380.x/abstract,

Accessed:10/01/2012

Parlamento Italiano

1990 Legge. n. 39, 28 febbraio, Rome.

Parlamento Italiano

1998 Testo Unico sull' Immigrazione Decreto Leggislativo, n. 286, 25 luglio, Rome.

Rossi, P.,

2008 "Qualitá e Risorse Umane", Universitá e Sitema Paese Consiglio Universitario Nazionale, 18 -20 of June, Rome.

Ruggio, L.,

2008 "Governance e Risorse Finanaziare" Universitá e Sitema Paese Consiglio Universitario

Nazionale, Rome 18 -20, Available at:

http://www.rientrodeicervelli.net/cun convegno 2008 06 18.pdf 
Accessed:10/01/2012 